\title{
Die Bydrae van Basiese Navorsing in Kliniese Toepassings met Verwysing na Kogleêre Inplantings
}

\author{
Tania Hanekom en Johan J. Hanekom
}

Departement Elektriese, Elektroniese en Rekenaar-Ingenieurswese

Universiteit van Pretoria

\section{OPSOMMING}

Hierdie artikel bespreek die waarde van basiese navorsing soos toegepas op kogleêre inplantings. Die artikel is gerig op klinici en oudioloë wat in die veld van kogleêre inplantings werk, of wat in hierdie veld belangstel. Die artikel gee ook 'n meer algemene inleiding tot modellering vir navorsers in die kliniese omgewing. Dit gee 'n wegspringpunt vir kogleêre inplanting navorsing en gee 'n oorsig oor die toepassing van basiese navorsing in nuwe ontwikkeling in kogleêre inplantings. Daar word gewys wat tot dusver bereik is en watter probleme nog bestaan. Die rol van multidissiplinêre navorsingspanne by die oplossing van hierdie probleme word bespreek. Eksperimentele navorsing en modellering werk saam om probleme op te los en nuwe ontdekkings te doen. Die belangrikheid van modellering as 'n gereedskapstuk vir basiese navorsing word beklemtoon.

\begin{abstract}
This article discusses the value of basic research as applied to cochlear implants. The article is aimed at clinicians and audiologists who are working in the field of cochlear implants or who are interested in this field. The article also gives a more general introduction to modelling for researchers in the clinical environment. It provides an entry point to cochlear implant research and reviews the application of basic research to new developments in cochlear implants. It is shown what has been achieved so far and which problems still exist. The role of multidisciplinary research teams to solve these problems is discussed. Experimental research and modelling co-operate to solve problems and make new discoveries. The importance of modelling as a tool for basic research is emphasized.
\end{abstract}

SLEUTELWOORDE: kogleêre inplantings, elektriese stimulasie, modellering, multidissiplinêre navorsing, basiese navorsing.

\section{INLEIDING}

Daar is dikwels die persepsie dat'n kloof bestaan tussen die wêrelde van die navorser en die klinikus. Die klinikus mag voel dat navorsing soms isoteriese probleme aanspreek wat van min praktiese waarde is. Daarenteen mag die navorser voel dat die klinikus nie genoeg begrip het van die onderliggende beginsels waarop sy of haar werk berus nie. Hierdie artikel spreek hierdie probleem aan uit die oogpunt van die navorser. Meer spesifiek, in hierdie artikel word menslike gehoor en kogleêre inplantings (Clark, 1993) gebruik as voertuig om te demonstreer watter basiese navorsing in hierdie veld nodig is en wat die praktiese impak daarvan vir die oudioloog en klinikus is. Die artikel is dus gerig op lede van die mediese span wie se betrokkenheid by gehoor en kogleêre inplantings primêr klinies van aard is (spesifiek oudioloë en klinici). Die doel is om te wys wat die rol en toepaslikheid van basiese navorsing is en ook om 'n begrip te vestig van die probleme wat navorsers aanspreek en die tegnieke wat hulle gebruik. 'n Omvattende bronnelys word ingesluit as inleiding tot die literatuur in die veld.
Die benadering wat in die artikel gevolg word, is om 'n beskrywing te gee van die aard van navorsing, asook die gereedskap en metodes wat navorsers gebruik en om die bydrae van basiese navorsing in neuroprostetiese rehabilitasie met spesifieke verwysing na kogleêre inplantings in perspektief te stel. Die artikel beklemtoon spesifiek modellering as 'n belangrike gereedskapstuk in basiese navorsing.

\section{DIE AARD VAN NAVORSING}

Navorsing in neuroprostetiese rehabilitasie kan in drie kategorieë verdeel word: kliniese navorsing, tegnologiese navorsing (ingenieurswese) en basiese navorsing. Kliniese navorsing is gemik op (1) die habilitasie en rehabilitasie van gestremde persone (spesifiek gehoorgestremde persone in hierdie artikel) deur die keuse van geskikte hulpmiddels uit dit wat beskikbaar is, (2) toepassing van die hulpmiddels (bv. die inplantering van prosteses), (3) navorsing omtrent die beste maniere om hierdie hulpmiddels te gebruik (insluitende verbeterde kliniese prosedures), en (4) die ontwikkeling van effektiewe nasorgiprogramme. 
Hierdie aspekte word hoofsaaklik bedryf deur oudioloë en klinici en val buite die bespreking van hierdie artikel.

Tegnologiese navorsing in neuroprostetiese rehabilitasie word hoofsaaklik bedryf deur ingenieurs, maar dit behoort duidelik te wees dat dit nie in isolasie kan gebeur nie. Ingenieurs ontwikkel nuwe hulpmiddels, dikwels na aanleiding van behoeftes wat gestel word deur gestremde mense of deur medici. Behoeftes mag bestaan-lank voor die tegnologie ver genoeg ontwikkel het om die spesifieke probleem te kan aanspreek. Kogleêre inplantings is een van die suksesverhale van biomediese ingenieurswese. Graham Clark het in die vorige eeu reeds besef dat die tegnologie ryp was vir 'n tegnologiese oplossing vir doofheid. Hoewel hy beskou word as een van die pioniers van hierdie tegnologie, het hy gebou op vorige navorsing (Andreef, Gersuni \& Volokhov, 1934; Brummer \& Turner, 1975; House \& Urban, 1973; Simmons, Mongeon, Lewis \& Huntington, 1964). 'n Verdere bespreking van die proses betrokke by die ontwikkeling van nuwe tegnologie val buite die bestek van hierdie artikel.

Basiese navorsing gee die grondslag waarop die praktiese oplossing van probleme gebou is, maar dit kan die uiteindelike tegnologiese toepassing met baie jare vooruitloop. Volta (1800) het byvoorbeeld reeds twee eeue terug die eerste keer met elektriese stimulasie geëksperimenteer. Toepassings, of potensiële toepassings, gee rigting aan basiese navorsing. Die doel van basiese navorsing is eerstens om 'n fundamentele onderbou te verskaf waarop kliniese toepassings en tegnologiese ontwikkeling baseer kan word. Twee voorbeelde word gegee. Eerstens, sonder die begrip van die elektriese stimuleerbaarheid van senuweeweefsel (bv. Galvani, 1791; Hodgkin \& Huxley, 1952), sou dit nie moontlik wees om die tegnologie van kogleêre inplantings te ontwikkel nie. Tweedens, die diagnostiese hulpmiddels wat in die oudiologie gebruik word, spruit voort uit die groot hoeveelheid navorsing in die psigoakoestiek wat oor die afgelope eeu gedoen is (Richards, 1976).

Basiese navorsing stel dus ten doel eerstens om 'n beter begrip te verkry van die fundamentele werking van die onderliggende biologie en fisiologie van 'n lewende stelsel en tweedens om die reaksie van die stelsel op spesifieke insette of stimuli te voorspel. Binne die konteks van neuroprosteses is die nut van basiese navorsing dus om (1) die wetenskaplike kennis omtrent die werking van die normale en elektries-gestimuleerde biologiese stelsel uit te brei (bv. Clark, Shute, Shepherd \& Carter, 1997; Shannon, 1993), (2) die funksionering van prosteses te verbeter deur nuwe kennis omtrent die werking van die biologiese stelsel toe te pas gedurende die ontwerp van nuwe generasies tegnologiese hulpmiddels (bv. Cords, Reuter, Issing, Sommer, Kuzma \& Lenarz, 2000), en (3) om die effek van elektriese stimulasie te verklaar vir verskillende inplantings wat op die mark beskikbaar is bv. (Tye-Murray, Tyler, Woodworth \& Gantz, 1992).

Hieronder word aangedui wat die navorsingsvrae omtrent kogleêre inplantings is en watter gereedskap gebruik word by navorsing. Eerstens word die probleem van kogleêre inplantings kortliks geskets.

\section{DIE KOGLEÊRE INPLANTINGSPROBLEEM}

Kogleêre inplantings kan vanuit beide 'n kliniese oogpunt en bio-ingenieurswese oogpunt beskou word as suksesvol (National Institutes of Health, 1995). Die inplantings is veilig en betroubaar. Kliniese prosedures en prosesse vir voorsorg, insorg en nasorg is gevestig. Inplantings is voordelig vir die gebruiker, vir wie dit in kontak plaas met die klankomgewing. Inplantings word ook as finansieel effektief beskou.

Daar is egter vele onopgeloste probleme, insluitend onvoorspelbaarheid van resultate (Clark, 1996), groot interpasiëntvariasie in sukses (Kou, Shipp \& Nedzelski, 1994), baie gebruikers se lae spraakverstaanbaarheid in 'n normale spraakomgewing (Kou, Shipp \& Nedzelski, 1994; Clark, 1996), meeste gebruikers se musiekpersepsie is swak (Fujita \& Ito, 1999), sommige gebruikers het steeds balansprobleme (Kou, Shipp \& Nedzelski, 1994), baie gebruikers kan nie telefonies kommunikeer nie en sukkel in ruiserige omstandighede (Hirsch, 1993). Die ideaal is dat'n gebruiker se inplanting onsigbaar van buite is, lang lewensduur het, lang batterylewe het en klankkwaliteit gee wat naby aan normale gehoor is.

Kogleêre inplantings se ontwerp is gebaseer op drie onderliggende beginsels: (1) 'n senuweevesel kan geaktiveer of gestimuleer word deur elektriese stroom deur die vesel te laat vloei, (2) senuweevesels in die koglea is tonotopies gerangskik (Greenwood, 1990) en (3) frekwensie-inligting word gekodeer in beide tydpatrone sowe as die plek van aktiwiteit in die cochlea (Evans, 1978).

Die tonotopiese rangskikking van die senuweevesels in die koglea verwys na die rangskikking van senuweevesels volgens toonhoogte oor die lengte van die koglea. Stimulasie van senuweevesels naaste aan die basis van die koglea is verantwoordelik vir persepsie van hoë toonhoogtes terwyl senuweevesels nader aan die apeks laer toonhoogtes waarneem. Deur dus stroom deur die senuweevesels te laat vloei op spesifieke plekke in die koglea, kan verskillende toonhoogtesensasies geskep word. Vokoder-tipe strategieë maak gebruik van hierdie idee (bv. die SPEAK strategie, Loizou, 1999). Daarenteen fokus strategieë soos CIS (Loizou, 1999) op die behoud van tydpatrone.

In teenstelling met akoestiese opwekking van senuwees in 'n normale koglea, word groot getalle senuweevesels gelyktydig geaktiveer tydens elektriese stimulasie (Javel, 1990). Een rede hiervoor is dat daar ongeveer 30000 senuwees in die koglea is (Allen, 1985) wat met slegs 16 tot 22 elektrodes geaktiveer moet word (Clark, 1993; Kessler, 1999). Verder kan die stimulasiestrategieë wat gebruik word om klanklinligting oor te dra nie die tyd- of ruimtelike patrone waarvolgens die gehoorsenuweevesels akoesties geaktiveer word perfek namaak nie (Javel, 1990; Miller, Abbas, Rubinstein, Robinson, Matsuoka \& Woodworth, 1998). Die stroomverspreiding om die elektrodes tesame met die stimulasiestrategie het waarskynlik' 'n groot effek op die klanksensasie wat 'n persoon met 'n kogleêre inplanting waarneem (Clark, 1996). Die uitdaging is dus om die verspreiding van die stimulasiestroom by die senuwees te beheer en om die stimulasiestrategie te optimeer in 'n poging om die natuurlike senuweeaktiveringspatrone in die koglea na te maak (Rubinstein, Wilson, Finley \& Abbas, 1999). Twee aanverwante navorsingsdoelwitte wat hieruit spruit, is (1) om metodes te vind om die verspreiding van die stimulasiestroom by die senuwees te beheer (bv. Cords, Reuter, Issing,'Sommer, Kuzma \& Lenarz, 2000) en om (2) die proses waarop die sentrale gehoorstelsel die inligting wat tydens stimulasie oorgedra word integreer, verwerk en interpreteer verder te ontsyfer (bv. Hanekom \& Krüger; 2001; Zeng \& Shannon, 1999) sodat die stimulasiestrategie daarvolgens ontwerp 
kan word. Dis byvoorbeeld nog nie duidelik of tyd- of plekkodering dominant is nie (Moore \& Sek, 1996).

\section{DIE GEREEDSKAP WAT GEBRUIK WORD VIR BASIESE NAVORSING}

Basiese navorsing in kogleêre inplantings sluit in neurofisiologiese laboratoriumeksperimente, psigoakoestiese eksperimente met normaalhorende persone sowel as gebruikers van inplantings, en modellering van die perifere en sentrale gehoorstelsel, beide wanneer dit akoesties gestimuleer word en wanneer dit elektries gestimuleer word.

Om die navorsingsdoelwitte genoem in die vorige paragraaf te kan behaal, bv. om die verspreiding van die stimulasiestroom te beheer en om die sentrale verwerkingsprosesse in die brein te verstaan, is dit belangrik om die fisiese en biologiese beginsels met standaardmetodes te kan naspeur en te kan beskryf. Analitiese navorsingstegnieke en prosedures in die neurofisiologie en psigoakoestiek is goed gevestig in standaardprosedures oor'n tydperk van baie dekades. Beskrywingstegnieke kom uit die domein van ingenieurs, fisici en wiskundiges.

\section{MODELLERING}

Ingenieurs skep dikwels wiskundige modelle om prosesse voor te stel en die effek van veranderings aan 'n stelsel te voorspel. 'n Model is ' $n$ wiskundige beskrywing van' 'n natuurlike verskynsel - in hierdie geval dus 'n wiskundige beskrywing van die werking van die sentrale gehoorstelsel of 'n wiskundige beskrywing van die geïnplanteerde koglea.

Die ingenieur of natuurwetenskaplike skep dus 'n stelsel van wiskundige vergelykings waarmee die gedrag van die normale gehoorstelsel of van die elektriesgestimuleerde gehoorstelsel beskryf kan word. Die vergelykings kan met analitiese metodes (bv. Rubinstein, Soma \& Spelman, 1985; Siebert, 1970) of met numeriese metodes (bv. Finley, Wilson \& White, 1990; Rattay \& Aberham, 1993) opgelos word. Numeriese oplossings word verkry met rekenaarsimulasies.

Modelle kan verder varieer vanaf streng biologiesgebaseerde modelle tot swartkassiemodelle. Die term swartkassiemodel word dikwels deur ingenieurs gebruik vir'n stelsel waarvan mens die inset en die uitset kan meet, maar geen kennis het óor wat binne-in die stelsel (die "swart kassie") sit nie. Voorbeelde word hieronder gegee.

Streng biologiesgebaseerde modelle daarenteen inkorporeer soveel moontlik bestaande kennis oor die biologiese anatomie en fisiologie. Sulke modelle mag byvoorbeeld die funksie van 'n spesifieke stelsel in die brein modelleer deur. 'n groot aantal senuwees te modelleer en dan hierdie senuwees saam te voeg in 'n groter struktuur (Bower, 1990). Meer spesifiek, in sulke modelle mag elke senuwee wat modelleer word beskryf word deur 'n volledige Hodgkin-Huxleymodel (Hodgkin \& Huxley, 1952). Die Hodgkin-Huxleymodel is een van 'n. aantal biologiesgetroue senuweemodelle en gebruik 'n hele aantal wiskundige vergelykings om die werking van 'n enkele senuweesel te beskryf.

Swartkassiemodelle beskryf bloot inset-uitsetdata deur 'n wiskundige vergelyking sonder die inagneming van die biologie. Sommige senuweemodelle modelleer die senuwee bloot as 'n generator van senuweepulse (bv. Gabbiani \&
Koch, 1996). In die eenvoudigste vorm pas swartkassiemodelle bloot ' $n$ kurwe aan die data en aanvaar geen begrip van die werking van die stelsel wat dit modelleer nie. Swartkassiemodelle kan baie beperk wees in terme van die datastelle wat voorspel kan word.

Tussen streng biologiese modelle en swartkassiemodelle bestaan ' $n$ hele kontinuum van modelle wat tot'n mindere of meerdere mate bestaande kennis oor die biologie inkorporeer. Sommige modelle ignoreer doelbewus bestaande kennis (dus is meer geïdealiseerd as streng biologiesgebaseerde modelle) met die doel om randfaktore buite rekening te laat (soos byvoorbeeld variasies tussen mense) om te kan deurdring tot die kernbewerkings wat die stelsel wat ondersoek word, uitvoer.

Modelle word gekarakteriseer deur die modelstruktuur en die parameters. Hierdie terme word met 'n voorbeeld verduidelik. Om 'n sekere funksie (bv. diskriminasie van twee suiwer tone) uit te voer is 'n netwerk van neurone op 'n sekere manier aan mekaar geskakel. Vir sommige stelsels in die liggaam is hierdie struktuur in minder of meer detail bekend, bv. struktuur van die piriforme korteks, die primêre sentrum vir die verwerking van olfaktoriese inligting (Bower, 1990), en die struktuur van die sentrale ouditiewe stelsel, (Brugge, 1992; Ehret, 1997). Wanneer die struktuur van 'n model gedefinieer word, moet daar onder andere besluit word hoeveel neurone die model moet bevat, wat die aard van die sinapse (inhiberend of eksiterend) moet wees, en wat die plasing van die sinapse in die struktuur moet wees. Die modelstruktuur kan afgelei word uit die anatomie (Bower, 1990). Nadat die struktuur bekend is, mag sekere parameters steeds onbekend wees. Die eienskappe van die senuweemembraan (bv. hoe sterk dit reageer op 'n stimulus), die spoed waarteen senuwees aksiepotensiale gelei en die dikte van die senuwees is voorbeelde van modelparameters. Bower (1990) gee 'n gedetailleerde voorbeeld van so'n rekenaarmodel vir die piriforme korteks.

Modellering is dikwels ' $n$ iteratiewe proses. Gegrond op die navorser se begrip van die prosessering wat uitgevoer word in die stelsel wat gemodelleer word, bepaal die navorser'n modelstruktuur. Parameters vir die model moet dan gemeet word, of kan soms uit die literatuur verkry word. Dikwels is dit nodig om modelparameters te skat en soms is dit voldoende as die skatting net naastenby reg is. Met struktuur en parameters bekend, kan rekenaarsimulasies dan met die model uitgevoer word. Die gedrag van die verskynsel wat gemodelleer word (die uitsette van die model), word tipies beskryf in terme van meetbare hoeveelhede soos byvoorbeeld die vuurtempo op enkelsenuwees, ruimtelike aktiveringspatrone op ' $n$ aantal senuwees, gehoordrempels en drempels van frekwensiediskriminasie. Dit is nodig dat die uitsette van 'n model ooreenstem met meetbare hoeveelhede sodat die werking van die model met fisiese metings bevestig kan word.

As die model se gedrag goed is, m.a.w. die model kan gemete data getrou namaak (dit kan absolute waardes en tendense voorspel), gee dit vertroue dat die keuse van die struktuur goed was. Soms word tendense reg voorspel, maar die groottes van die gemete data en voorspelde data stem nie ooreen nie. Dit kan wees omdat die struktuur van die model reg is, maar die parameters foutief geskat of gemeet is. Aan die ander kant kan dit gebeur dat die model hoegenaamd glad nie die gemete data kan voorspel nie, en dan is die eerste vermoede dat die modelstruktuur verkeerd is. 
'n Belangrike vraag wat oor elke model beantwoord moet word is: Kandie model gemete data buite die datastel waarvoor die model geskep is, verklaar? Indien nie, moet die model verder ontwikkel word. Hoe meer datastelle 'n model kan verklaar, hoe meer vertroue kry die navorser dat die verwerking van die onderliggende stelsel verstaan word en dat die model se struktuur dus reg is. As voorbeeld, as ' $n$ model geskep is om frekwensiediskriminasie van enkeltone te voorspel, maar dit kan ook die diskriminasie van komplekse tone voorspel, gee dit heelwat vertroue in die geldigheid van die model. Soos modelle verder ontwikkel word, groei begrip van die stelsel wat gemodelleer word.

\section{WAARVOOR WORD MODELLE GEBRUIK?}

Modelle van die gehoorstelsel kan nie die effek van stimulasie of die gedrag van die gehoorstelsel perfek voorspel nie, omdat hulle 'n vereenvoudiging van die werklikheid voorstel. Dit is byvoorbeeld onmoontlik om al die interpersoonvariasies in die aantal residuele senuwees in die kogleas van dowe persone in ag te neem. Wat is die nut van modelle dan? 'n Volmaakte voorstelling van die werklikheid is nie noodwendig noodsaaklik, of beskikbaar, om die funksionering van 'n stelsel te beskryf nie. Kogleêre inplantings is 'n goeie voorbeeld hiervan, omdat verbeterings aan die inplantings reeds suksesvol aangebring is op grond van onder andere modelleringstudies, ten spyte daarvan dat die funksionering van die gehoorstelsel nie volledig verstaan word nie (Clark, 1996). As 'n model dus die belangrikste eienskappe van 'n stelsel só korrek kan voorspel dat die inligting bruikbaar is, is die model nuttig. Heelwat modelle is byvoorbeeld geskep om psigoakoestiese data te voorspel vanuit neurofisiologiese data. Sulke modelle het onlangs gewys dat ruis 'n positiewe rol speel in gehoor (Bruce, White, Irlicht, O'Leary \& Clark, 1999; Zeng, Fu \& Morse, 2000). Op grond hiervan is nuwe algoritmes voorgestel wat meer ruis sal bewerkstellig in vuurpatrone as gevolg van elektriese stimulasie (Bruce, Irlicht, White, O'Leary, Dynes, Javel \& Clark, 1999; Bruce, White, Irlicht, O'Leary \& Clark, 1999; Rubinstein, Wilson, Finley \& Abbas, 1999; White, Rubinstein \& Kay, 2000).

Modelle van die geïnplanteerde koglea is ook geskep om die stroomverspreiding om die elektrodes te voorspel (Finley, Wilson \& White, 1990; Frijns, de Snoo \& Schoonhoven, 1995; Girzon, 1987; T. Hanekom, 2001; Rattay, Leao \& Felix, 2000). Hierdie modelle het gewys dat senuwees meer selektief gestimuleer kan word as die elektrodes nader aan die senuwees geplaas word. Op grond van modelleringsdata soos hierbo en metings in die laboratorium (Shepherd, Hatsushika \& Clark, 1993) is nuwe elektrodes, soos naby-modiolus elektrodes (Donnelly, Cohen, Xu, Xu \& Clark, 1995; Treaba, Xu, Xu \& Clark, 1995), en 'n elektrodeposisioneerder (Cords, Reuter, Issing, Sommer, Kuzma \& Lenarz, 2001), ontwikkel.

Nog 'n belangrike gebruik van betroubare modelle is dat dit die navorser in staat stel om konsepte te toets in rekenaarsimulasies, eerder as om direk eksperimente op mensè of diere te doen.

\section{EKSPERIMENTELE NAVORSING}

Eksperimentele navorsing sluit'n wye veld in en is gerig op die fisiese kwantifisering van parameters waarvoor daar ontwerp moet word in neuroprostetiese toestelle. Ekspe- rimentele navorsing is nader aan die verwysingsraamwerk van die klinikus of oudioloog en sal nie hier in diepte bespreek word nie. Slegs enkele navorsingsgebiede word ter illustrasie genoem.

Ingenieursaspekte wat tipies tydens basiese navorsing aangespreek word sluit in bio- aanpasbaarheid, veiligheid en betroubaarheid van die materiale wat geïnplanteer word (Brummer \& Turner, 1975; Clark, Shepherd, Patrick, Black \& Tong, 1983; Donaldson, Donaldson \& Brindley, 1985; Hambrecht, 1985; House \& Urban, 1973; Lenhart, 1992; Seldon, Dahm, Clark \& Crowe, 1994; Van Noordt \& Black, 1981); betroubaarheid van die stelsel (Soma, 1986); korrosie van die elektrodemateriale (Donaldson \& Donaldson, 1986; Donaldson, Donaldson \& Brindley, 1985; Hanekom \& Hanekom, 1998; Johnson \& Hench, 1977; Shepherd, Murray, Houghton \& Clark, 1985); vervaardiging van elektrodes, geïnplanteerde elektronika en eksterne elektronika (Clark, Shepherd, Patrick, Black \& Tong, 1983; Hanekom, Hanekom \& Marais, 1998; Lauridsen, Günthersen, Bonding \& Tos, 1982); en betroubaarheid van elektronika en hermetiese verseëling (Donaldson, 1988; Soma, 1990).

Neurofisiologiese eksperimente is gerig op die bepaling van die biologiese stelsel se eienskappe en werking waarbinne die prostese moet funksioneer. In kogleêre prosteses is kennis oor die werking van senuweevesels en die seinverwerking deur die senuweevesels en sentrale gehoorstelsel van primêre belang. Fisioloë het meettegnieke ontwikkel en metings gedoen op senuwees om die meganisme waarvolgens senuwees geaktiveer word na te speur (Frankenhaeuser, 1956; Hodgkin \& Huxley, 1952; Schwarz \& Eikhof, 1987), om eienskappe van senuwees te meet (Verveen, 1962), om senuwees se reaksie op elektriese stimulasie te meet (Miller, Abbas, Rubinstein, Robinson, Matsuoka \& Woodworth, 1998; Rattay, 1999; Rubinstein, Wilson, Finley \& Abbas, 1999; Shepherd, Hatsushika \& Clark, 1993; Stypulkowski \& van den Honert, 1984; van den Honert \& Stypulkowski, 1984; van den Honert \& Stypulkowski, 1987a; van den Honert \& Stypulkowski, $1987 \mathrm{~b}$ ) en om skade aan senuwees as gevolg van elektriese stimulasie te bepaal (Huang \& Shepherd, 1999; McCreery, Agnew, Yuen \& Bullara, 1992; Shepherd, Matsushima, Martin \& Clark, 1994; Tykocinski, Shepherd \& Clark', 1997).

Die doel met psigoakoestiese eksperimente is om die waarneembare effek van insette na die gehoorstelsel te kwantifiseer. Psigoakoestiese hoeveelhede soos die toonhoogte of luidheid van 'n klank is persoonafhanklik' en kan nie eenduidig en direk gemeet word nie. Psigoakoestiese hoeveelhede word dus statisties bepaal nadat proefpersone 'n voldoende aantal herhalings van'n eksperiment voltooi het om 'n statisties beduidende resultaat te lewer. Deur die psigoakoestiek van akoestiese en elektriese stimulasie te vergelyk (J.J. Hanekom, 2000; Shannon, 1993; Zeng \& Shannon, 1992) kan meer geleer word oor die seinverwerking wat die gehoorstelsel doen en oor hoe om te werk te gaan om beter inplantings té ontwikkel. Psigoakoestiese navorsing kan direk lei tot verbeterde algoritmes (Clark, 1996) en verbeterde programmering van bestaande inplantings (Hanekom \& Shannon, 1996).

\section{NAVORSING MOET MULTIDISSIPLINÊR WEES}

Die bespreking hierbo wys dat-multidissiplinêre navor- 
singspanne nodig is om probleme effektief aan te spreek en nuwe tegnologie te ontwikkel. Natuurwetenskaplikes soos ingenieurs, fisioloë, fisici, wiskundiges en dierkundiges beskik oor die eksperimentele en analitiese gereedskap wat nodig is om die suiwer wetenskaplike en tegnologiese aspekte ter sprake by basiese navorsing op die gebied van kogleêre inplantings aan te spreek. Elke lid van 'n navorsingspan kan nie 'n kundige wees op elke tersaaklike gebied nie. Ingenieurs het 'n goeie teoretiese en tegnologiese onderbou en kan fokus op modellering, die ontwikkeling van meetgereedskap en tegnologie. Fisioloë kan weer fisiologiese parameters meet op selle of diere in die laboratorium. Kliniese en basiese navorsing het verskillende (maar aanverwante) doelwitte. In 'n multidissiplinêre span word beide tipes navorsing gedoen, en al die lede van die span kan betrokke wees by alle navorsingsprojekte, maar tipies word kliniese en basiese navorsing afsonderlik bestuur deur 'n klinikus en 'n natuurwetenskaplike onderskeidelik.

\section{WAT IS REEDS BEREIK MET BASIESE NAVORSING?}

Enkele voorbeelde word hier gegee van die impak van basiese navorsing op die ontwikkeling van kogleêre inplantings. Dit is in psigoakoestiese eksperimente bepaal dat die frekwensie waarteen gestimuleer word op'n enkele elektrode net gediskrimineer kan word tot omtrent 300 $\mathrm{Hz}$, maar dat deur die plek van stimulasie te verskuif, 'n baie groter perseptuele verandering in frekwensie verkry kan word as $300 \mathrm{~Hz}$ (Dorman, Smith, Smith \& Parkin, 1994; Shannon, 1983). Ander navorsing het gewys dat die elektrodes gerangskik kan word in tonotopiese volgorde (Dorman, Smith, Dunnavant, Parkin \& Dankowski, 1990; Nelson, Van Tasell, Schroder, Soli \& Levine, 1995). Daarom is besluit om frekwensie te kodeer as plek van stimulasie in al die bestaande multikanaalinplantings (Clark, 1996; Kessler, 1999).

In 'n verdere lyn van navorsing is aangetoon dat die elektries-gestimuleerde gehoorstelsel net so goed of beter vaar as die normale' 'gehoorstelsel met take wat tydresolusie meet (Shannon, 1983; Shannon, 1989; van Wieringen \& Wouters, 1999). Hierdie lyn van navorsing het gelei tot strategieë wat daarop gemik is om die tydpatrone in spraak so getrou as moontlik in stimulasiegolfvorms na te maak, bv. die CIS strategie (Loizou, 1999).

\section{WAT IS HUIDIGE NAVORSINGSVRAE?}

Daar is 'n te groot aantal navorsingsvrae wat tans aangespreek word om almal hier te noem. Enkele belangrike vrae word genoem. Kan stroomverspreiding rondom elektrodekontakte beperk word deur beter elektrode-ontwerpe (Cords, Reuter, Issing, Sommer, Kuzma \& Lenarz, 2000)? Hoeveel interaksie is daar tussen neurale kanale wat met verskillende elektrodes gestimuleer word (Fu, 1997; Hanekom \& Shannon, 1998)? Is kanaalinteraksie belangrik vir spraakverstaanbaarheid (Fu \& Shannon, 1999a; Fu \& Shannon, 1999b)? Is dit plekkodering of tydkodering, of:'n kombinasie van beide die meganismes waarmee die gehoorstelsel frekwensie kodeer (J.J. Hanekom, 2000; Moller, 1999)? Hoeveel elektrodes is nodig vir effektiewe oordraging van inligting aan die elektriesgestimuleerde gehoorstelsel (Fishman, Shannon \& Slattery, 1997)? Hoe belangrik is die relatiewe tydverskille waarmee elektries gestimuleer word op die verskillende kanale (Carlyon, Geurts \& Wouters, 2000)? Waar presies word die elektriese gestimuleerde seine gegenereer (Javel \& Shepherd, 2000)? Wat is die invloed van die stimulasiegolfvorm se parameters op die klank wat waargeneem word (Chatterjee, Fu \& Shannon, 2000)? Hierdie is maar 'n klein uittreksel uit vrae, waarvan die antwoorde kan lei tot verbeterings in kogleêre inplantings.

\section{GEVOLGTREKKING}

Om die kogleêre inplanting-navorsingsveld volledig aan te spreek is dit noodsaaklik dat basiese navorsing in parallel met kliniese navorsing gedoen moet word. Kliniese navorsing konsentreer op die habilitering en rehabilitering van die dowe persoon, terwyl basiese navorsing gemik is op uitbreiding van die kennis en begrip van die werking van die normale en elektries-gestimuleerde gehoorstelsel sowel as die ontwikkeling en verbetering van die kogleêre inplantingtegnologie.

Basiese navorsing behoort modelgebaseerd te wees. Wiskundige modelle vorm 'n belangrike deel van die meetgereedskap van die navorser. Buiten hul waarde om bestaande kennis op te som, dra modelle by tot begrip van die werking van die stelsel (bv. die gehoorstelsel). Modelle help ook om gapings in die bestaande kennis bloot te lê, hetsy dit in onbekende parameterwaardes of in begrip van die werking van die stelsel lê.

Basiese navorsing het reeds gelei tot kliniese toepassings waaronder die kogleêre inplanting een van die uitstaande suksesse is. 'n Verskeidenheid van moeilike navorsingsprobleme is egter onopgelos en sal georkestreerde pogings van multidissiplinêre navorsingspanne benodig om die volgende kwantumsprong in inplantingtegnologie te maak.

\section{BRONNELYS}

Allen, J. B. (1985). Cochlear modeling. IEEE Acoustics, Speech and Signal Processing Magazine, January, 3-29.

Andreef, A. M., Gersuni, G. V. \& Volokhov, A. A. (1934). Electrical stimulation of the hearing organ. Journal of Physiology USSR, 17, 546-559.

Bower, J. M. (1990). Reverse engineering of the nervous system: an anatomical, physiological, and computer-based approach. An introduction to neural and electronic networks. Academic Press.

Bruce, I. C., Irlicht, L. S., White, M. W., O'Leary, S. J., Dynes, S., Javel, E. \& Clark, G. M. (1999), A stochastic model of the electrically stimulated auditory nerve: Single-pulse response. IEEE Transactions on Biomedical Engineering, 46(6), 617-629.

Bruce, I. C., White, M. W., Irlicht, L. S., O'Leary, S. J. \& Clark, G. M. (1999). Effects of stochastic neural activity in a model predictive intensity perception with cochlear implants: Lowrate stimulation. IEEE Transactions on Biomedical Engineering, 46, 1393-1404.

Brugge, J. F. (1992). An overview of central auditory processing. In Popper, A. N. and R.R.Fay, The mammalian auditory pathway: neurophysiology New York: Springer-Verlag.

Brummer, S. B. \& Turner, M. J. (1975). Electrical stimulation of the nervous system: The principle of safe charge injection with noble metal electrodes. Bioelectrochemistry and Bioenergetics, $2,13-25$.

Carlyon, R. P., Geurts, L. \& Wouters, J. (2000). Detection of small across-channel timing differences by cochlear implantees. Hearing Research, 141, 140-154.

Chatteriee, M., Fu, Q-J. \& Shannon, R. V. (2000). Effects of phase duration and electrode separation on loudness growth in cochlear implant listeners. Journal of the Acoustical Society of America, 107(3), 1637-1644.

Clark, G. M. (1993). The development of the Nucleus multiple- 
channel cochlear implant. Australian Journal of Otolaryngology, 1(4), 310-316.

Clark, G. M. (1996). Electrical stimulation of the auditory nerve: the coding of frequency, the perception of pitch and the development of cochlear implant speech processing strategies for profoundly deaf people. Clinical and Experimental Pharmacology and Physiology, 23, 766-776.

Clark, G. M., Shepherd, R. K., Patrick, J. F., Black, R. C. \& Tong, Y. C. (1983). Design and fabrication of the banded electrode array. Annals of the New York Academy of Sciences, 405, 191201

Clark, G. M., Shute, S. A., Shepherd, R. K. \& Carter, T. D. (1995). Cochlear implantation: Osteogenesis, electrode-tissue impedance, and residual hearing. Annals of Otology, Rhinology and Laryngology Supplement (United States), 166, 40-42.

Cords, S. M., Reuter, G., Issing, P. R., Sommer, A., Kuzma, J. \& Lenarz, T. (2000). A silastic positioner for a modiolus-hugging position of intracochlear electrodes: Electrophysiologic effects. American Journal of Otology, 21, 212-217.

Donaldson, N. d. N. \& Donaldson, P. E. K. (1986). When are actively balanced ('Lilly') stimulating pulses necessary in a neurological prosthesis? II pH changes; Noxious products; Electrode corrosion; Discussion. Medical and Biological Engineering and Computing, 24, 50-56.

Donaldson, P. E. K. (1988). Technical note: Testing hermetic seals of microelectronic packages. Journal of Medical Engineering and Technology, 12(1), 26-27.

Donaldson, P. E. K., Donaldson, N. d. N. \& Brindley, G. S. (1985). Life of $\mathrm{Pt}$ and $\mathrm{Pt}$-Ir stimulating electrodes in neurological prostheses. Medical and Biological Engineering and Computing, 23, 84-86.

Donnelly, M. J., Cohen, L. T., Xu, J., Xu, S. A. \& Clark, G. M. (1995). Investigations on a curved intracochlear array. Annals of Otology, Rhinology and Laryngology Supplement (United States), 166, 409-412.

Dorman, M. F., Smith, L., Dunnavant, G., Parkin, J. \& Dankowski, K. (1990). Pitch scaling and speech understanding by patients who use the Ineraid cochlear implant. Ear and Hearing, 11(4), 310-315.

Dorman, M. F., Smith, M., Smith, L. \& Parkin, J, L. (1994). The pitch of electrically presented sinusoids. Journal of the Acoustical Society of America, 95(3), 1677-1679.

Ehret, G. (1997). The auditory midbrain, a "shunting yard" of acoustical information processing. In Ehret, G. and R.Romand, The central auditory system New York: Oxford University Press.

Evans, E. F. (1978). Place and time coding of frequency in the peripheral auditory system: some physiological pros and cons. Audiology, 17, 369-420.

Finley, C. C., Wilson, B. S. \& White, M. W. (1990). Models of neural responsiveness to electrical stimulation. In Miller, J. M. and F.A.Spelman, Cochlear Implants. Models of the electrically stimulated ear New York: Springer-Verlag.

Fishman, P. M., Shannon, R. V. \& Slattery, W. H. (1997). Speech recognition as a function of the number of electrodes used in the SPEAK cochlear implant speech processor. Journal of Speech and Hearing Research, 40, 1201-1215.

Frankenhaeuser, B. (1956). A method for recording resting and action potentials in the isolated myelinated nerve fibre of the frog. Journal of Physiology, 135, 550-559.

Frijns, J. H. M., de Snoo, S. L. \& Schoonhoven, R. (1995). Potential distributions and neural excitation patterns in a rotationally symmetric model of the electrically stimulated cochlea. In Frijns, J. H. M., Cochlear Implants. A Modelling Approach Den Haag: CIP-Data Koninklijke Bibliotheek.

Fu Q.-J. , Chatterjee, M., Hanekom, J. J., Shannon, R. V., Zeng F.-G. (1997). Comparison of electrode interaction measures in multichannel cochlear implants. Poster presentation at 1997

Conference on Implantable Auditory Prostheses, Asilomar, CA August 16-20.

Fu, Q.-J. \& Shannon, R. V. (1999a). Effects of electrode configuration and frequency allocation on vowel recognition with the Nucleus-22 cochlear implant. Ear and Hearing, 20(4), 332-344.

Fu, Q.J. \& Shannon, R. V. (1999b). Effects of electrode location and spacing on phoneme recognition with the Nucleus-22 cochlear implant. Ear and Hearing, 20(4), 321-331.

Fujita, S. \& Ito, J. (1999). Ability of nucleus cochlear implantees to recognize music. Annals of Otology, Rhinology and
Laryngology, 108, 634-640.

Gabbiani, F. \& Koch, C. (1996). Coding of time-varying signals in spike trains of integrate- and-fire neurons with random threshold. Neural Computation, 8, 44-66.

Galvani, L. (1791). De viribus electricitatis in motu muscalari, commentarius. De Bononiensi Scientiarum Et Artium Instituto Atque Academia, 7, 363-418.

Girzon, G. (1987). Investigation of current flow in the inner ear during electrical stimulation of intracochlear electrodes. MS Thesis in EE\&CS, MIT, Cambridge, Massachusetts.

Greenwood, D. D. (1990). A cochlear frequency-position function for several species - 29 years later. Journal of the Acoustical Society of America, 87(6), 2592-2605.

Hambrecht, F. T. (1985). Principles for building biocompatible devices: Safety considerations. In Schindler, R. A. and M.M.Merzenich, Cochlear Implants New York: Raven Press.

Hanekom, J. J. (2000). What do cochlear implants teach us about the encoding of frequency in the auditory system? South African Journal of communication Disorders, 47.

Hanekom, J. J. \& Krüger, J. J. (2001). A model of frequency discrimination with optimal processing of auditory nerve spike intervals. Hearing Research, 151(1-2), 188-204.

Hanekom, J. J. \& Shannon, R. V. (1996). Place pitch discrimination and speech recognition in cochlear implant users. The South African Journal of Communication Disorders, 43, 27 40.

Hanekom, J. J. \& Shannon, R. V. (1998). Gap detection as a measure of electrode interaction in cochlear implants. Journal of the Acoustical Society of America, 104(4), 2372-2384.

Hanekom, T. (2001). Three-dimensional spiraling finite element model of the electrically stimulated cochlea. Ear and Hearing, in druk.

Hanekom, T. \& Hanekom, J. J. (1998). On the design of implantable electrodes for electrical nerve stimulation. South African Journal of Science, 94, 307-310

Hanekom. T., Hanekom, J. J. \& Marais, P. (1998). Actively deposited ceramic layers as insulation on thin implantable electrode conductors. South African Journal of Science, 94, $310-311$.

Hirsch, H. G. (1993). Intelligibility improvements of noisy speech for people with cochlear implants. Speech Communication, 12 , $261-266$.

Hodgkin, A. L. \& Huxley, A. F. (1952). A quantitative description of membrane current and its application to conduction and excitation in nerve. Journal of Physiology, 117, 500-544.

House, W. F. \& Urban, J. (1973). Long term results of electrode implantation and electronic stimulation of the cochlea in man. Annals of Oto-Rhino-Laryngology, 82(4), 504-516.

Huang, C. Q. \& Shepherd, R. K. (1999), Reduction in excitability of the auditory nerve following electrical stimulation at high stimulus rates. IV. Effects of stimulus intensity. Hearing Research, 132, 60-68.

Javel, E. (1990). Acoustic and electrical encoding of temporal information. In Miller, J. M. and F.A.Spelman, Cochlear implants: models of the electrically stimulated ear New York: Springer- Verlag.

Javel, E. \& Shepherd, R. K. (2000). Electrical stimulation of the auditory nerve. III. Response initiation sites and temporal fine structure. Hearing Research, 140, 45-76.

Johnson, P. F. \& Hench, L. L. (1977). An in vitro analysis of metal electrodes for use in the neural environment. Brain. Behav.Evol., 14, 23-45.

Kessler, D. K. (1999). The Clarion multi-strategy cochlear implant Annals of Otology, Rhinology and Laryngology, 108, 8-16.

Kou, B. S., Shipp, D. B. \& Nedzelski, J. M. (1994). Subject benefits reported by adult Nucleus 22-channel cochlear implant users. Journal of Otolaryngology (Canada), 23(1), 8-14.

Lauridsen, O., Günthersen, C., Bonding, P. \& Tos, M. (1982). Experiments with a thinfilm multichannel electrode for cochlear implantation. Acta Otolaryngologica, 95, 219-226.

Lenhart, E. (1992). Biocompatibility of cochlear implants. Eur. Arch. Otorhinolaryngol. Suppl. (Germany), 13(2), 223-233.

Loizou, P. C. (1999). Signal-processing techniques for cochlear implants. IEEE Engineering in Medicine and Biology, 18(3), 34-46.

McCreery, D. B., Agnew, W. F., Yuen, T. G. H. \& Bullara, L. A. (1992). Damage in Peripheral Nerve from Continuous Electrical Stimulation: Comparison of Two Stimulus Waveforms. Medical and Biological Engineering and 
Computing, 30, 109-114.

Miller, C. A., Abbas, P. J., Rubinstein, J. T., Robinson, B. K., Matsuoka,A. J. \& Wood worth, G. G. (1998). Electrically evoked compound action potentials of guinea pig and cat: responses to monopolar, monophasic stimulation. Hearing Research, 119, 142-154.

Moller, A. R. (1999). Review of the roles of temporal and place coding of frequency in speech discrimination. Acta Otolaryngologica (Stockholm), 119, 424-430.

Moore B. C. J. \& Sek, A. (1996). Detection of frequency modulation at low modulation rates: evidence for a mechanism based on phase locking. Journal of the Acoustical Society of America, 100(4), 2320-2331.

National Institutes of Health (1995). Cochlear implants in adults and children. NIH Consensus Statement, May 15-17, 13(2), 130.

Nelson, D. A., Van Tasell, D. J., Schroder, A. C., Soli, S. \& Levine, S. (1995). Electrode ranking of "place pitch" and speech recognition in electrical hearing. Journal of the Acoustical Society of America, 98(4), 1987-1999.

Rattay, F. (1999). The basic mechanism for the electrical stimulation of the nervous system. Neuroscience, 89, 335-346.

Rattay, F. \& Aberham, M. (1993). Modeling axon membranes for functional electrical stimulation. IEEE Transactions on Biomedical Engineering, 40(12), 1201-1209.

Rattay, F., Leao, R. N. \& Felix, H. (2000). A model of the electrically excited human cochlear neuron. II. Influence of the 3dimensional cochlear structure on neural excitability. Hearing Research.

Richards, A. M. (1976). Basic experimentation in psychoacoustics. Baltimore: University Park Press.

Rubinstein, J. T., Soma, M. \& Spelman, F. A. (1985). Mixed boundary value problems in the implanted cochlea: An analytical model of a cylindrical banded electrode array. IEEE Seventh Annual Conference of the Engineering in Medicine and Biology Society, 1120-1123.

Rubinstein, J. T., Wilson, B. S., Finley, C. C. \& Abbas, P. J. (1999), Pseudospontaneous activity: stochastic independence of auditory nerve fibers with electrical stimulation. Hearing Research, 127, 108-118.

Schwarz, J. R. \& Eikhof, G. (1987). Na currents and action potentials in rat myelinated nerve fibres at 20 and 30 degrees C. Pflügers Archiv, 409, 569-577.

Seldon, H. L., Dahm, M. C., Clark, G. M. \& Crowe, S. (1994). Silastic with polyacrylic acid filler: Swelling properties, biocompatibility and potential use in cochlear implants. Biomaterials, 15, 1161-1169.

Shannon, R. V. (1983). Multichannel electrical stimulation of the auditory nerve in man. I. Basic psychophysics. Hearing Research, 11, 157-189.

Shannon, R. V. (1989). Detection of gaps in sinusoids and pulse

trains by patients with cochlear implants. Journal of the Acoustical Society of America, 85(6), 2587-2592.

Shannon, R. V. (1993). Quantitative comparison of electrically and acoustically evoked auditory perception: implications for the location of perceptual mechanisms. Progress in Brain Research, 97, 261-269.

Shepherd, R. K., Hatsushika, S.-I. \& Clark, G. M. (1993). Electrical stimulation of the auditory nerve. The effect of electrode position on neural excitation. Hearing Research, 66, 108- 120 .

Shepherd, R. K., Matsushima, J., Martin, R. L. \& Clark, G. M. (1994). Cochlear pathology following chronic electrical stimulation of the auditory nerve: II. Deafened kittens. Hearing Research, 81(1-2), 150-166.

Shepherd, R. K., Murray, M. T., Houghton, M. E. \& Clark, G. M. (1985). Scanning electon microscopy of chronically stimulated platinum intracochlear electrodes. Biomaterials, 6, 237-242.

Siebert, W. M. (1970). Frequency discrimination in the auditory system: place or periodicity mechanisms? Proceedings of the IEEE, 58(5), 723-730.

Simmons, F. B., Mongeon, C. S., Lewis, W. R. \& Huntington, D. A. (1964). Electrical stimulation of acoustical nerve and inferior colliculus: results in man. Archives of Otolaryngology, $79,559-567$.

Soma, M. (1986). Reliability of implantable electronic devices. Two case studies. IEEE Transactions on Reliability, R-35, 483487.

Soma, M. (1990). A package design technique for size reduction of implantable bioelectronic systems. IEEE Transactions on Biomedical Engineering, 37, 482-488.

Stypulkowski, P. H. \& van den Honert, C. (1984). Physiological properties of the electrically stimulated auditory nerve. I. Compound action potential. Hearing Research, 14, 205-223.

Treaba, C. G., Xu, J., Xu, S. A. \& Clark, G. M. (1995). Precurved electrode array and insertion tool. Annals of Otology, Rhinology and Laryngology Supplement (United States), 166, 438-441.

Tye-Murray, N., Tyler, R. S., Woodworth, G. G. \& Gantz, B. J. (1992). Performance over time with Nucleus or Ineraid cochlear implant. Ear and Hearing, 13(3), 200-209.

Tykocinski, M., Shepherd, R. K. \& Clark, G. M. (1997). Reduction in excitability of the auditory nerve following electrical stimulation at high stimulus rates. II. Comparison of fixed amplitude with amplitude modulated stimuli. Hearing Research, 112, 147-157.

Van den Honert, C. \& Stypulkowski, P. H. (1984). Physiological properties of the electrically stimulated auditory nerve. II. Single fiber recordings, Hearing Research, 14, 225-243.

Van den Honert, C. \& Stypulkowski, P. H. (1987a). Single fiber mapping of spatial excitation patterns in the electrically stimulated auditory nerve. Hearing Research, 29, 195-206.

Van den Honert, C. \& Stypulkowski, P. H. (1987b). Temporal response patterns of single auditory nerve fibers eliceted by periodic electrical stimuli. Hearing Research, 29, 207-222.

Van Noordt, R. \& Black, M. M. (1981). Silicone rubbers for medical applications. In Williams, D. F., Biocompatibility of Clinical Implant Materials: Vol II Florida: CRC Press Inc.

Van Wieringen, A. \& Wouters, J. (1999). Gap detection in singleand multiple-channel stimuli by LAURA cochlear implantees. Journal of the Acoustical Society of America, 106(4), 19251939.

Verveen, A. A. (1962). Axon diameter and fluctuation in excitability. Acta Morphol.Neerl.Scand., 5, 79-85.

Volta, A. (1800). Letter to Sir Joseph Banks, March 20, 1800. On electricity excited by the mere contact of conducting substances of different kinds. Philisophical Transactions of the Royal Society, 90, 403-431.

White, J. A., Rubinstein, J. T. \& Kay, A. R. (2000). Channel noise in neurons. Trends in Neurosciences, 23, 131-137.

Zeng, F.-G., Fu, Q.J. \& Morse, R. P. (2000). Human hearing enhanced by noise. Brain Research, 869, 251-255.

Zeng, F.-G. \& Shannon, R. V. (1992). Loudness balance between electric and acoustic stimulation. Hearing Research, 60, 231235.

Zeng, F.-G. \& Shannon, R. V. (1999). Psychophysical laws revealed by electric hearing. NeuroReport, 10, 1931-1935 


\section{Time to think of a change?}

\section{Think}

about

working in the UK

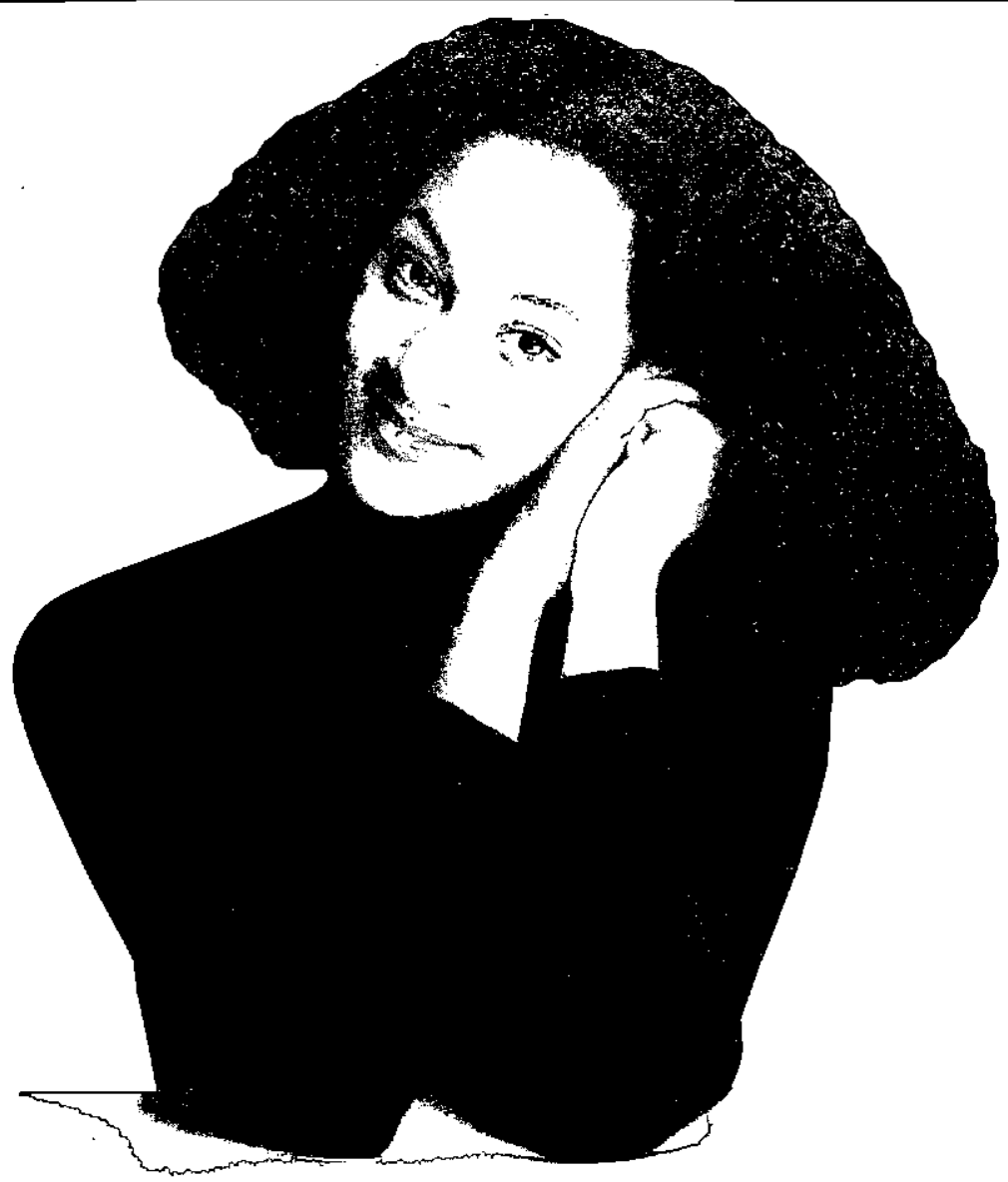

\section{Speech and Language Therapists and Audiologists}

Quality Locums are looking for quality personnel in all grades and specialities for work in the UK. Eligibility for a visa or work permit would be an advantage, but even if you are not eligible we would still like to hear from you as we may be able to help. Quality Locums are the largest independent Medical, Care and Education Agency in the UK and we have branches in South Africa and Australia. We need Medical Staff of all specialities, Social Workers and Teachers urgently to fill full and part time positions throughout Great Britain and Ireland. We are experts at helping you to take advantage of the opportunities in the UK. Why not call one of our managers today for an informal discussion.

Sonja Lewis - Quality Locums Cape Town Tel: 0214625357

Fax: 0214625390

Email: QualityLocums@Worldonllne.co.za

Matt Wagner - Quality Locums Durban rel: 0314692098

Email Wagner@yebo.co.za

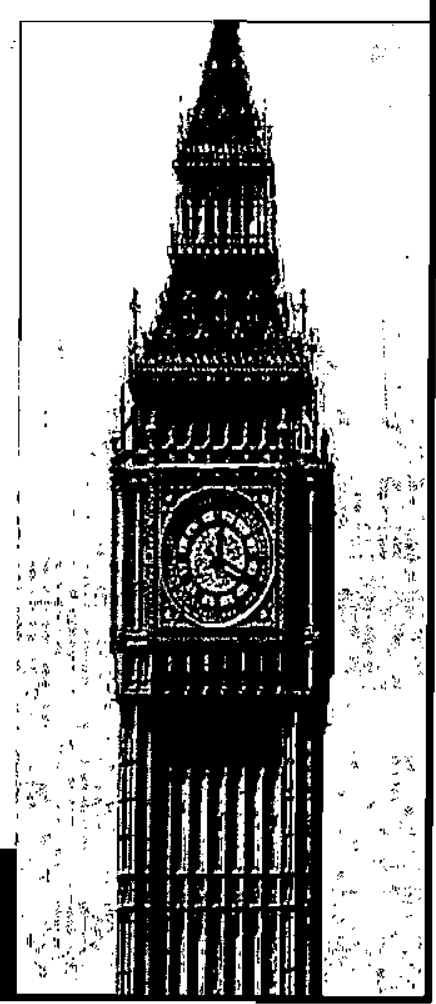

